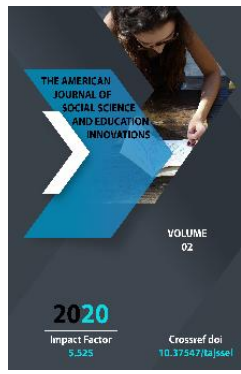

\title{
Cognitive Linguistics In Language Learning Process
}

\author{
Najimova G. B. \\ Teacher Of Faculty Of Foreign Languages, Karakalpak State University, Uzbekistan \\ Kartbaeva N. \\ Student Of Faculty Of Foreign Languages, Karakalpak State University, Uzbekistan
}

Copyright: Original content from this work may be used under the terms of the creative commons attributes 4.o licence.

\section{ABSTRACT}

Cognitive linguistics is concerned with language in use, viewing language as a social phenomenon rather than simply a series of rules and structures. It is on this sense that this paper addresses the specific and essential roles of it in the English classroom from the perspective of cognitive linguistics. The article deals with the contribution of cognitive linguistics to the learning process with miming and body language.

\section{KEYWORDS}

Linguistics, phenomena, lexical chunks, context, categories, vocabulary acquisition, miming, gesture.

\section{INTRODUCTION}

Cognitive linguistics is one important interdisciplinary branch of cognitive science, and is closely related to cognitive psychology and linguistics. It is also an approach to language, which views language as a kind of cognitive action, and studies the formation, the meaning, and the rules of language with cognition as its departure. In short, cognitive linguistics is an approach that is "based on our experience of the world and the way we perceive and conceptualize it [6;95] Cognitive Linguistics ( $\mathrm{CL}$ )provides tools that may help language teachers to gain insight into the semantic potential of words and communicate the meaning of lexical chunks in greater detail and with regard to collocations with greater explanatory power. It is said that applied $\mathrm{CL}$ can contribute to teaches' language awareness 
and it can broaden the scope of lexical awareness [5].

The use of linguistics in education is continuing to grow and is often cross-disciplinary in nature. Not only is it utilized by language instructors, it is also used in early childhood development psychology and anthropology education, as well. Linguistics is not only the study of language, but also introduces the evaluation and historical context of language, speech and memory development. It includes the structure and meaning of speech, and of written languages as well as an understanding of the context in which certain words are used [3]. When teaching a foreign language, linguistics is so vital to language teachers in that providing historical context to better master the language. This is especially important when it comes to among conversational speech, formal speech and abstract rules about word usage in different cultures. This can actually overlap into regional dialects within the same country. Although cognitive linguistics is a new marginal discipline which has a history of twenty years or so, it does not only broaden our belief about the word 'cognition', but also has striking influence on the study of the process of second and foreign language learning and teaching [6;97]. As an example, cognitive approach to the teaching of grammar to ESL learners seems to be a feasible solution to some problems. Unlike school students, graduates to learn ESL oftentimes need explanation when it comes to grammar. Course books for university students traditionally offer sets of grammar rules accompanied by examples and exercises to foster the knowledge acquired, which does not necessarily lead to a correct understanding and, therefore, use of, say, the appropriate tense form. As regards teaching grammar at university level, cognition as the characteristic underlying learner communicative competence has been scrutinized by researchers into applied linguistics and language teaching. Cognitive linguistics presents a view of language linked to the embodied nature of meaning, and offers opportunities for a certain kind of classroom activity. In short, it is grammar put [1:21].

Nowadays, in this modern pase of our life, society's understanding, perception of the world is getting different, in addition to this, educational system also requires new initiatives in teaching young generations in effective ways. Especially, in Uzbekistan learning English is must to pursue high results for everyone and learners are also acclimatizing to comprehending new languages easily. As we know, there are a lot of methods to teach language to ESL students, but, from my point of view, while explaining vocabulary, using cognitive linguistics can work and be effective way. As linguist David Wilkins points out that "Without grammar very little can be conveyed, without vocabulary nothing can be conveyed" [5:95].

\section{MATERIALS AND METHODS}

This best saying about the importance of vocabulary learning has been welcomed by teachers and learners for many years. Most learners, too, acknowledge the importance of vocabulary acquisition. Here are some statements made by some English learners:

- Firstly, vocabulary is very important. It measures a man's English level.

- My problem is that I forget the words soon after I have looked in the dictionary. And I cannot recognize them whenever I come across in reading English books. 
- I want to enlarge my vocabulary. I have the feeling that I always use the same expressions to express different sort of things. I can't find right way that works well ti learn them by heart

However, vocabulary teaching has not always been very responsive to such problems, and teachers have not fully recognized the tremendous communicative advantage in developing an extensive vocabulary.

Implications of cognitive linguistics for classroom English vocabulary instruction Zhao Yanfang, a well-known scholar specialized in the study of Cognitive Linguistics (CL) in China, proposed that at least three principles based on $C L$ can be used to direct our teaching of vocabulary, that is, the study of categorization, prototype, and metaphor.

\section{RESULT AND DISCUSSION}

According to Zhao, categorization is the classification of things in the cognitive process, which is essentially mental. Correspondingly, the process that the subject interacts with the object and classifies is a process of categorizing. And it is on this basis that we can conceptualize and make sense of the world around us. More important, categories and categorizations exist everywhere, and there are ways we perceive the world, otherwise we cannot know it in appropriate way. As well as, many teachers and scholars get enlightens from the cognitive vocabulary teaching strategies and put some cognitive linguistics theories into the classroom practice. In the teaching practice, teachers can use cognitive theories to help students understand why a word has so many different meanings and the origin of its different meanings [7:45] As everybody knows, while learning English language beginners preferably count on the basic-level category vocabulary and apply them to the communication. That's why; there is a need to explain polysemy in English with this theory: For every polysemy there is a core meaning and other additional forms extended from the core meaning. For example:

\begin{tabular}{|c|c|}
\hline 1.Body & $\begin{array}{l}\text { 1. Originally refers to our physical parts, } \\
\text { including our heads, arms, legs. } \\
\text { 2. Also, it is used to refer to the main part of } \\
\text { other objects, such a car, or a building. } \\
\text { 3. It is applied to a large area of a water, the } \\
\text { main part of a document or a thesis an } \\
\text { organised group of people who deal with } \\
\text { something officially. }\end{array}$ \\
\hline 2.Open & $\begin{array}{l}\text { 1."spread out" } \\
\text { 2. honest. } \\
\text { 3.not hidden } \\
\text { 4.not covered }\end{array}$ \\
\hline
\end{tabular}




\begin{tabular}{|l|l|}
\hline \multirow{3}{*}{ 3un } & 5. available \\
\hline 4.Spring & $\begin{array}{l}\text { 1. to move very quickly, by moving your legs } \\
\text { more quickly than you walk. } \\
\text { 2. to organize or be in charge of an activity, } \\
\text { business organization or country. } \\
\text { 3.to operate, to use } \\
\text { 1.the act of springing a leap } \\
\text { 2. a place where a stream of water comes } \\
\text { out of earth. } \\
\text { 3. a season of the year. }\end{array}$ \\
\hline
\end{tabular}

As we see above, there are many polysemous words and in such situation, teaching vocabulary with the help of theory is a good idea for teachers to explain the basic meaning first and then deduce other meanings from them. In this case, every effective way that works successfully is essential and the next one can be using mimes and gestures in teaching language. Alan Cienki in his work "Cognitive Linguistics, gesture studies, and multimodal communication" pointed t"If speakers are thinking in terms of imagery from the metaphoric source domain, we might expect to see some representation of that imagery in their gestures" [2]. Our brain receives information during the conversation mostly from our body language and this can normally connected the theory. In order to explain basic vocabulary that is used during the lesson for ESL class, applying body language is one of the approach. As an example, holding out 2 arms with your hands open and your palms down, then move your hands up and down means "calm down", miming and looking over to what is written on the next desk and then show disapproval with crossed arms a finger dragged side to side, an angry face to mean "do not cheat or copy" and with your actions you ask learners what this or other actions mean and they quickly try to find the exact word.

In $\mathrm{CL}$, human mind gets to know things at the middle level, on which we know objects most easily, and the categories in this level is thus called basic level category. And vocabulary that comes into existence on the basis of the basic categories goes to basic level vocabulary. These vocabularies share a most distinctive attribute bundles that help to distinguish them 
from other vocabularies: less time to recognize, high frequency of use, and the most widely used items in everyday communication. Consequently, in our present teaching of English vocabulary, enough attention and great importance should be given to the acquisition and instruction of basic vocabularies [6:97].

\section{CONCLUSION}

Several attempts have been made to connect cognitive principles and foreign language teaching in different aspects, and many useful suggestions have been provided to teaching methodology and learning strategies in L2 classrooms. However, most contributions made to highlight the usefulness of the $\mathrm{CL}$ disciplines have not been empirically validated but only subject to theoretical and pedagogically suggestive descriptions; in addition, efforts have been made primarily in lexis teaching/learning, e.g., the imageschema-based instruction of polysemous words and enhancement of metaphoric awareness in learning idiomatic expressions [8]. As well as it can be used to teach grammatical structures, and we can apply it to the teaching of prepositions, conditionals and modals. We suggest that its effectiveness depends on the teacher's mastery to create enough exposure to the target language and to apply relevant theoretical basis to ensure that learners develop the target knowledge and skills, and furthermore and on the learner's engagement in communicative language practice. In studies of second language acquisition there is empirical evidence that the classroom application of cognitive linguistic theories can improve student outcomes in reading and writing, too [4:65] It seems to me that there is a clear motivation for exploring its use in the classroom of native learners, as part of an evolving discussion about what effective grammar teaching could and should involve. Language teachers should know both how to make the constructions of the target language in harmony with the nature of the processor (i.e., human mind) and how to present them to make successful acquisition happen.

\section{REFERENCES}

1. A.S Druzhinin,O.G Polyakov. A Cognitive Approach to teaching present perfects to ESL learners.Derzhavin Tambov State University, Tambov Moscow State Institute of International Relations, Moscow.p-21

2. Alan Cienki. Cognitive Linguistics, gesture studies, and multimodal communication: Cognitive Linguistic Volume 27, Issue 4. De Gruyter Mouton 2016

3. https://work.chron.com/importancelinguistics-language-teacher-

14459.html-grow

4. Olga A. Obdalova.Exploring the Possibilities of the Cognitive Approach for Non-linguistic EFL Students Teaching.p-65

5. Ralf Gießler. Teacher language awareness and cognitive linguistics $(\mathrm{CL})$ : building a $\mathrm{CL}$-inspired perspective on teaching lexis in EFL student teachers.

6. Yanqin Chen.A Cognitive Language Approach to Classroom English Vocabulary. Instruction for EFL Learners in Mainland China. Kunming 650221.China.March. 2009. pp-95-97

7. Yan Zhao.Application of Cognitive Linguistics in English Vocabulary teacing.Yantai Nanshan 
The American Journal of Social Science and Education Innovations (ISSN - 2689-100x)

Published: December 31, 2020 | Pages: 407-412

Doi: https://doi.org/10.37547/tajssei/Volume02Issue12-70

2020: $5 \cdot 525$

OCLC - 1121105668

University.Yantai,Shandong,China.265

706.p-45.

8. Yu-Da-Li. A Cognitive Linguistics

Approach to Language

Teaching:Processing Instruction of

Iconicity in EFL Classrooms. Providence

University.December.2011.p-49 